\title{
Improving Hydrologic Modeling Using Cloud-Free MODIS Flood Maps
}

\author{
Hoang Tran, Phu Nguyen, Mohammed Ombadi, and Kuolin Hsu \\ Center for Hydrometeorology and Remote Sensing, Department of Civil and Environmental Engineering, \\ University of California, Irvine, Irvine, California \\ SOROOSH SOROOSHIAN
}

Center for Hydrometeorology and Remote Sensing, Department of Civil and Environmental Engineering, and Department of Earth System Science, University of California, Irvine, Irvine, California

\section{KONSTANTINOS ANDREADIS}

Department of Civil and Environmental Engineering, University of Massachusetts Amherst, Amherst, Massachusetts

(Manuscript received 29 January 2019, in final form 5 September 2019)

\begin{abstract}
Flood mapping from satellites provides large-scale observations of flood events, but cloud obstruction in satellite optical sensors limits its practical usability. In this study, we implemented the Variational Interpolation (VI) algorithm to remove clouds from NASA's Moderate Resolution Imaging Spectroradiometer (MODIS) Snow-Covered Area (SCA) products. The VI algorithm estimated states of cloud-hindered pixels by constructing three-dimensional space-time surfaces based on assumptions of snow persistence. The resulting cloud-free flood maps, while maintaining the temporal resolution of the original MODIS product, showed an improvement of nearly $70 \%$ in average probability of detection (POD) (from 0.29 to 0.49 ) when validated with flood maps derived from Landsat- 8 imagery. The second part of this study utilized the cloudfree flood maps for calibration of a hydrologic model to improve simulation of flood inundation maps. The results demonstrated the utility of the cloud-free maps, as simulated inundation maps had average POD, false alarm ratio (FAR), and Hanssen-Kuipers (HK) skill score of 0.87, 0.49, and 0.84, respectively, compared to POD, FAR, and HK of $0.70,0.61$, and 0.67 when original maps were used for calibration.
\end{abstract}

\section{Introduction}

Flood mapping using the rapid-response Moderate Resolution Imaging Spectroradiometer (MODIS) surface reflectance product is effective due to the product's global coverage and accuracy (Brakenridge and Anderson 2006). One of noticeable studies, the MODIS Water Product (MWP) was created using two bands, red and near-infrared (NIR), with a spatial resolution of $250 \mathrm{~m}$ (Policelli and Slayback 2017). When validating with 53 flood events in 2013 and 2014, MWP captured 44\% of the events from good (which means about half of the water-covered area is detected) to almost perfect (which means just about all of the water-covered area is detected; Nigro et al. 2014). More details of the evaluation process are referred to in Nigro et al. (2014).

\footnotetext{
Corresponding author: Hoang Tran, htranvie@uci.edu
}

Flood maps are an important input for the calibration of hydrologic and flood inundation models. Dynamic flood simulations by hydrologic models are beneficial for both operational applications and disaster management (Bates and De Roo 2000; Begnudelli et al. 2008; Andreadis et al. 2013; Nguyen et al. 2015, 2016; Krajewski et al. 2017; Condon and Maxwell 2019). Hence, coupling flood inundation models with observations from space for accurate simulations has been carried out for nearly three decades. Moll and Overmars (1990) were pioneers in calibrating a 1D hydraulic model by Landsat TM. In recent years, flood extent maps from satellite synthetic aperture radar (SAR), such as Envisat ASAR and ERS-2 SAR, were used to calibrate hydraulic models (Di Baldassarre et al. 2009; Hostache et al. 2009; Gobeyn et al. 2017).

However, clouds are major limitations to flood mapping from space. During extreme events such as hurricanes or 
storms, clouds often block satellites' visible band sensors from capturing floods (Alsdorf et al. 2007). Despite the importance of cloud removal, current studies attempting to remove clouds from flood maps are still in an early stage. To the best of our knowledge, the only effort to remove clouds from flood maps came from the same group (Policelli and Slayback 2017) when they created composite flood maps for 2, 3, and 7 days. While this approach was appropriate in some cases, it increased the product's latency (Nigro et al. 2014), which might fail to capture events that occur between the composite days.

To maintain the product's original temporal resolution while eliminating clouds, this study proposed the Variational Interpolation (VI) algorithm (Turk and O'Brien 1999) as an alternative data-driven method. VI is a three-dimensional (3D) interpolation method which employs available boundary information in space and time to construct a complete 3D surface of an object. It has been used effectively in removing clouds from MODIS's Snow-Covered Area (SCA) products (Xia et al. 2012; Tran et al. 2019). To appropriately apply VI for this problem, an assumption of water-covered body persistent characteristics at the temporal and spatial resolutions of MODIS needed to be made. It assumed the interpolation condition that water-covered boundaries change gradually with respect to VI's space and time steps.

The cloud-free flood maps represented a continuous and reliable source for hydrologic studies specifically intended to improve flood inundation model simulations. Daily MODIS flood maps were used to calibrate hydrologic models; providing frequent flood images unlike other sources that suffer from latency and lengthy revisit-time satellites such as Landsat TM (16 days), Envisat ASAR (35 days), and ERS-2 SAR (35 days).

Overall, the scope of this study was twofold: 1) apply the VI to recover satellite-based flood maps by removing cloud pollution, and 2) calibrate a hydrologic model with the resulting cloud-free flood maps to improve inundation simulations. The performance of the algorithm in recovering flood maps and the calibration scheme were evaluated using derived flood images from Landsat- 8 products.

\section{Study area and data}

\section{a. Study area}

The upper Mississippi River basin (UMRB; Fig. 1), which has an area of $308810.2 \mathrm{~km}^{2}$ and ranges between $40^{\circ} 20^{\prime}$ and $47^{\circ} 50^{\prime} \mathrm{N}$ in latitude and from $97^{\circ} 20^{\prime}$ to $88^{\circ} 12^{\prime} \mathrm{W}$ in longitude, is a major basin in the United States.

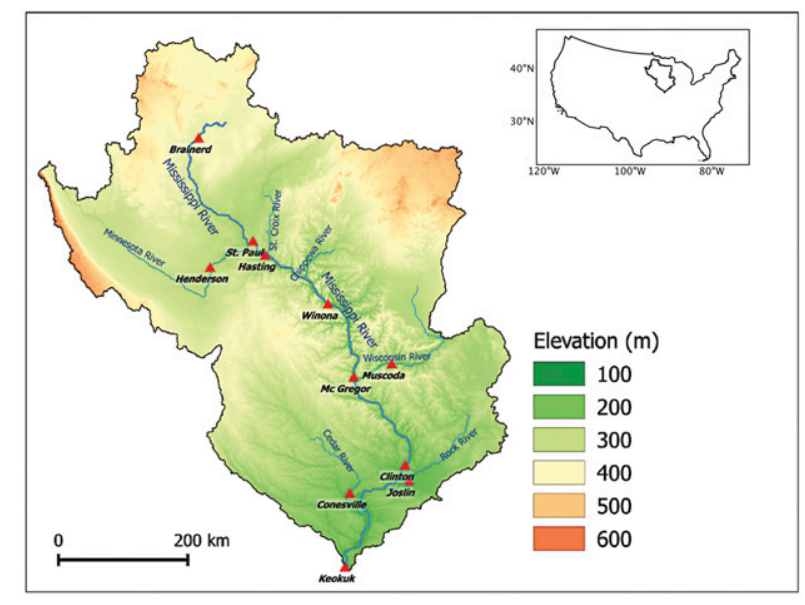

FIG. 1. The upper Mississippi River basin.

The basin is often prone to summer floods and historically speaking, extreme floods occurring in 1927, 1993, and, more recently, in 2014.

The UMRB includes seven rivers (Mississippi River, Minnesota River, St. Croix River, Chippewa River, Wisconsin River, Rock River, and Cedar River), whose floodplains can range between 5 and $80 \mathrm{~km}$ (according to the Upper Mississippi River Basin Association; UMRBA 2003). Hence, flooding in the UMRB could be well portrayed under MODIS's spatial resolution of $250 \mathrm{~m}$.

Last, the UMRB is well monitored with 11 U.S. Geological Survey (USGS) stations (Brainerd, USGS 05242300; Henderson, USGS 0532700; St. Paul, USGS 05331000; Hasting, USGS 05331580; Winona, USGS 05378500; McGregor, USGS 05389500; Muscoda, USGS 05407000; Clinton, USGS 05420500; Joslin, USGS 05446500; Conesville, USGS 05465000; and Keokuk, USGS 05474500). Data from these stations was used for model calibration and validation.

\section{b. Data}

Two products from version 6 of NASA's MODIS Surface Reflectance Daily level-2 gridded (L2G) were used in this study. While MOD09GQ/MYD09GQ (Vermote and Wolfe 2015b) provided the surface spectral reflectance of MODIS bands 1 and 2 at 250-m spatial resolution, MOD09GA/MYD09GA (Vermote and Wolfe 2015a) provided surface reflectance from MODIS bands 1-7 at 500-m and 1-km spatial resolutions. Both were corrected for atmospheric conditions such as gasses, aerosols, and Rayleigh scattering. Bands 1 and 2 of the MOD09GQ were main inputs to produce 250-m resolution MODIS flood maps. Bands 3-7 and azimuth and zenith angles information from MOD09GA were used to detect and remove cloud 
shadows from resulting flood maps [see section 3a(2) for more detail].

As mentioned, Policelli and Slayback (2017) used MOD09GQ as input to produce MWP. Before land/watercovered area discrimination, they used a daily cloud mask product from MODIS, which has spatial resolution of $1-\mathrm{km}$ to mask out cloud pixels. Water-covered pixels were then classified based on the reflectance ratio of NIR band to red band. Pixels were classified as water-covered if the ratio was smaller than 0.7 (D. Slayback 2018, personal communication). To detect flood pixels, Policelli and Slayback (2017) employed the MOD44W product, version 6 (Carroll et al. 2017), as the reference water-covered layer (i.e., if the water-covered pixel did not coincide with MOD44W, it would be considered as a flood pixel).

The MOD44W version 6 used the Shuttle Radar Topography Mission (SRTM) Water Body Dataset (NASA 2019) as a reference. Water-covered pixels were determined daily using a decision-tree algorithm and then accumulated into a 16-day reference watercovered product. More technical details can be found in the MOD44W user guide (Carroll et al. 2017).

To validate resulting images, derived flood maps from Landsat- 8 satellite were used. Landsat- 8 satellite captured the entire Earth every 16 days at high spatial resolution (i.e., around $30 \mathrm{~m}$ ). To produce flood maps from Landsat, we used the normalized difference water index (NDWI; McFeeters 1996). For more detail, please see section 4a.

With images which have fewer than $15 \%$ area covered by clouds, we collected the Landsat- 8 Operational Land Imager (OLI) Surface Reflectance (SR) Level-1 Terrain (L1T) product from the EarthExplorer website (USGS 2019). Using OLI sensor, ground control points (CGPs), and DEMs, the employed L1T product has been corrected radiometrically and geometrically (USGS 2018). More details about calibration and correction processes can be found in the Landsat-8 Users Handbook (USGS 2018).

Streamflow data were available in both hourly and daily time scales, which were quality controlled by USGS (USGS 2016). The National Oceanic and Atmospheric Administration (NOAA) precipitation product, Stage IV (Lin 2011), was produced by integrating data from 12 contiguous U.S. River Forecast Centers. It has around $4-\mathrm{km}$ spatial resolution and hourly and daily temporal resolutions. Evapotranspiration data, on the other hand, are important for drought and water resource management but not as critical for rainfall-driven flooding events. Hence, to reduce computing resources, we chose the monthly mean evapotranspiration data from the Famine Early Warning System Network (FEWSNET; FEWSNET 2019) with a spatial resolution of $1^{\circ}$, calculated on a

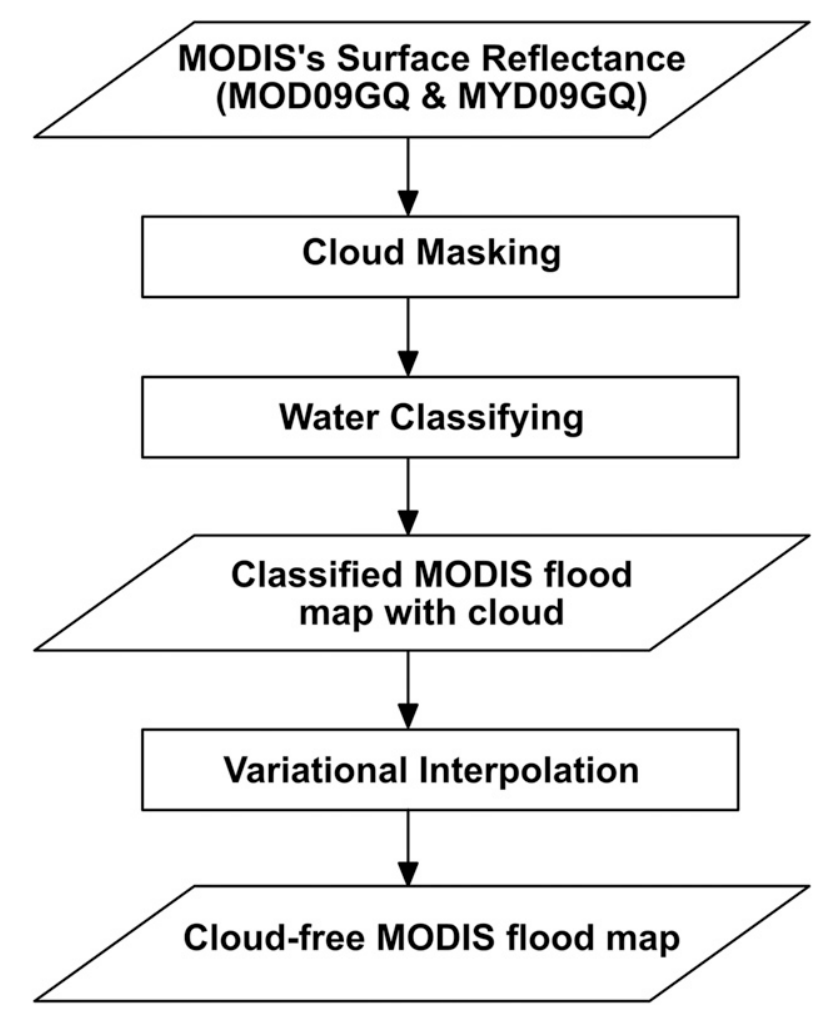

FIG. 2. Flowchart of the cloud removal process.

spatial basis using the Penman-Monteith equation (Monteith 1965, 1973).

The elevation data used in this paper were from the SRTM, version 3.0, from the EarthExplorer website (USGS 2019). The product had 30-m spatial resolution with all voids eliminated.

\section{Methods}

\section{a. Development of cloud-free flood maps}

Figure 2 presents a sequence of steps to produce cloud-free flood maps. These steps are illustrated in the subsequent subsections.

\section{1) Cloud MASKING}

From the original MODIS reflectance products, we started by masking all the cloud pixels thus keeping only ground pixels. Due to the distinguishable reflectance of clouds at different wavelength bands (Fig. 3), we proposed a threshold of reflectance between 0.8 and 0.9 in the red band (band 1 ) of MODIS to mask clouds, all pixels whose red band's reflectance values are greater than 0.8 and smaller than 0.9 were masked as clouds. We found this threshold guarantees low false positive rates in identifying cloud pixels. 
Reflectance of Clouds and Different Surface in the Visible to Shortwave Infrared

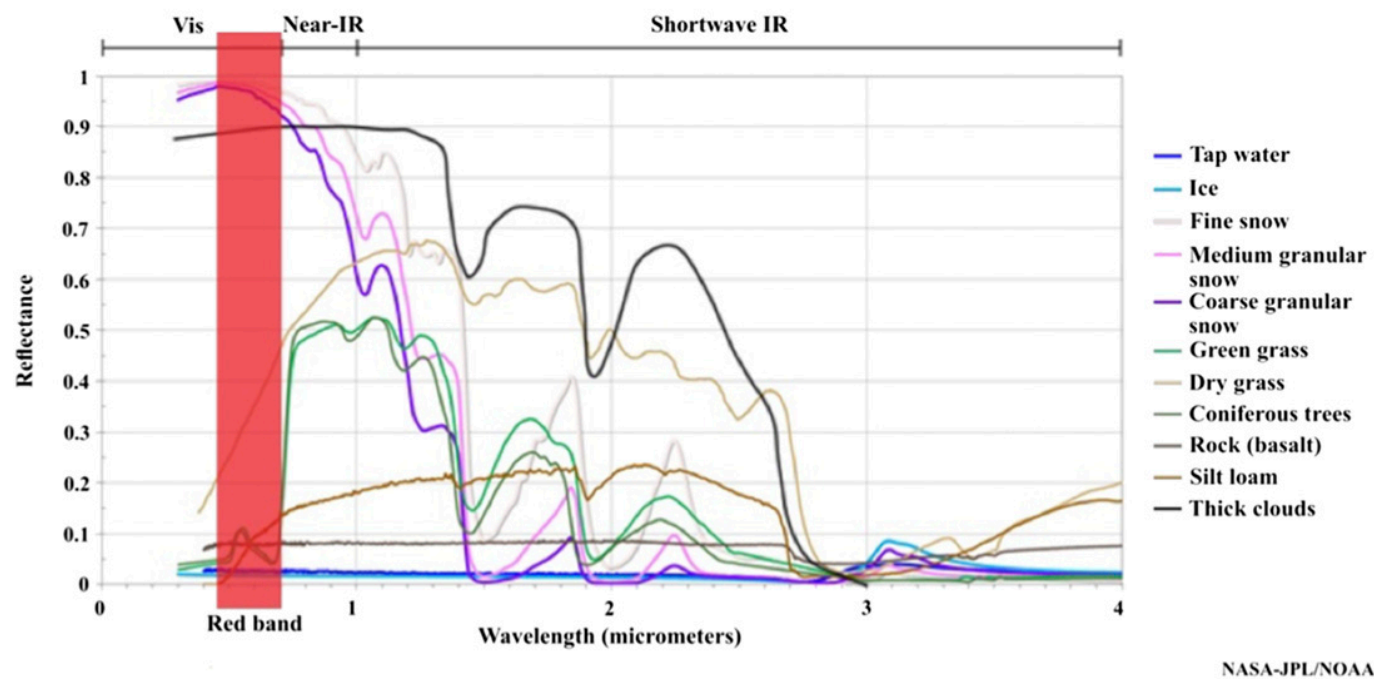

FIG. 3. Cloud and surface reflectance in the visible and shortwave infrared (image originally courtesy of NASA-JPL and NOAA).

Afterward, the obtained images with noncloud pixels were used as inputs for the next step of classifying watercovered pixels.

\section{2) IDENTIFICATION OF WATER-COVERED PIXELS}

Similar to the approach used in MWP, we utilized Brakenridge's algorithm to detect water based on an empirically derived reflectance ratio MODIS (band 2/band 1) threshold, if the pixel has the ratio was smaller than 0.7 , it would be classified as water-covered (D. Slayback 2018, personal communication). Moreover, to overcome the problem of mistakenly identifying cloud shadows as water, we adopted a scheme that combines geometric and spectral approaches to determine cloud shadow locations (Luo et al. 2008). According to this approach, from a cloud position on the image $\left(x_{\text {cloud }}, y_{\text {cloud }}\right)$, the nadir projection $\left(x_{\text {nadir }}, y_{\text {nadir }}\right)$ of cloud on the ground was determined based on height of cloud above the surface $\left(h_{c}\right)$, viewing zenith and azimuth angles $\left(\theta_{v}\right.$ and $\phi_{v}$, clockwise from true north), and the azimuth angle of true north from the $y$ axis $(\gamma)$ :

$$
\begin{aligned}
& x_{\text {nadir }}=x_{\text {cloud }}+h_{c} \tan \theta_{v} \sin \left(\phi_{v}+\gamma\right), \\
& y_{\text {nadir }}=y_{\text {cloud }}+h_{c} \tan \theta_{v} \cos \left(\phi_{v}+\gamma\right) .
\end{aligned}
$$

Then the projection of cloud shadow ( $x_{\text {shadow }}, y_{\text {shadow }}$ ) was determined by solar zenith and azimuth angles $\left(\theta_{s}\right.$ and $\left.\phi_{s}\right)$ :

$$
\begin{aligned}
& x_{\text {shadow }}=x_{\text {nadir }}+h_{c} \tan \theta_{s} \sin \left(\phi_{s}+\gamma\right), \\
& y_{\text {shadow }}=y_{\text {nadir }}+h_{c} \tan \theta_{s} \cos \left(\phi_{s}+\gamma\right) .
\end{aligned}
$$

Identified cloud shadow areas were masked out. It is noteworthy that due to the lack of precise cloud height determination, Luo et al. (2008) assumed a range of cloud height from 0.5 to $12 \mathrm{~km}$ to computed cloud shadow positions based on the range. We also followed the same approach. More details would be referred back to Luo et al. (2008).

The classified MODIS flood maps generated from this step still had missing data where cloud pixels were masked in the first step. Next, we proceeded to estimate ground states of cloud-hindered pixels via VI.

\section{3) VARIATIONAL INTERPOLATION}

The VI has been effectively used in Xia et al. (2012) and Tran et al. (2019) to remove cloud from MODIS's SCA product. These studies were based on the hypothesis that the interpolation algorithm works best with smooth 3D implicit surfaces. Hence, an assumption about the dynamic property of watercovered body boundaries had to be made. Given two reasons-1) MODIS provides two images of a place in one day and 2) its red and NIR bands have high spatial resolutions-we hypothesized that MODIS can capture gradual changes of watercovered bodies.

In this study, we only summarize the main process of VI implementation and refer interested readers to Xia et al. (2012) and Tran et al. (2019) for more details about the algorithm.

VI modeled the time-varying water-covered bodies by a $3 \mathrm{D}$ implicit function formulated as 


$$
f(\mathbf{x}) \begin{cases}>0 & \text { inside water body } \\ =0 & \text { at water body boundaries } \\ <0 & \text { outside water body }\end{cases}
$$

where $\mathbf{x}=\left(\begin{array}{lll}x_{1} & x_{2} & t\end{array}\right)^{\mathrm{T}} \in R^{3}, x_{1}$ and $x_{2}$ are spatial coordinates on the projection plane, and $t$ is the time. Once the water-covered body implicit surface in space and time was determined, cloud-free images from selected days could then be obtained through cross sections of the surface (Xia et al. 2012; Tran et al. 2019).

A representation of smooth implicit surfaces can be approximated as a linear combination of radial-basis functions established at selected constraint points on the surface (Duchon 1977; Xia et al. 2012):

$$
f(\mathbf{x})=0 \Rightarrow \sum_{i=1}^{N} w_{i} R\left(\mathbf{x}-\mathbf{x}_{i}\right)=0 .
$$

Here, $\left\{w_{i}\right\}$ is a set of $N$ weights and $\left\{R\left(\mathbf{x}-\mathbf{x}_{i}\right)\right\}$ is a selected radial-basis function established at $N$ constraints points. As in Xia et al. (2012) and Tran et al. (2019), we decided to use the thin plate function $R()=.r^{2} \log r$ with $r=\left\|\mathbf{x}-\mathbf{x}_{i}\right\|$ to present the radialbasis function.

With constraint points collected on water-covered body boundaries in discrete time, the weights of those points were computed by solving the linear system to create the implicit surface.

To provide VI with necessary constraint points, the Douglas-Peucker algorithm was used (Douglas and Peucker 1973). This algorithm simplifies water-covered body boundaries based on a relative distance dimension parameter $\varepsilon(0<\varepsilon<1)$ and returns a set of crucial points which both ensure preserving shapes of boundaries and reducing the number of points fed into the VI algorithm.

\section{4) CReating the ClOUd-Free images}

Regarding the use of VI algorithm, an interpolation period of 15 days was selected to examine the balance between accuracy and computational efficiency. The day selected was centered in this interpolation period in order to effectively utilize flood extents information. Daily cloud-free flood maps were created by using a moving window approach with a 1-day increment.

\section{5) Determining the Flooded AREA}

To identify flooded areas, we compared water-covered pixels in the map with the static water-covered layers (MOD44W; Carroll et al. 2017). Specifically, if a watercovered pixel fell outside the boundary of static watercovered bodies, it would be identified as a flooded pixel.

\section{b. Improvement of hydrologic modeling}

As mentioned earlier, a primary objective of this study was to use the developed cloud-free MODIS flood maps to improve hydrologic modeling. The hydrologic model used in this study was the Ensemble Framework for Flash Flood Forecasting (EF5; Flamig et al. 2015). Traditionally, the model's runoff and routing parameters are optimized/calibrated with gauge observations to improve the model performance. With the increasing availability of remotely sensed observations, other hydrologic model parameters such as inundation could also be calibrated, leading to more accurate simulations from the model.

In this subsection, we briefly introduce the hydrologic model framework (EF5) and the calibration scheme.

\section{1) ENSEMBle FrameWORK FOR FlASH FloOd FORECASTING}

EF5 (Flamig et al. 2015) is a C ++ based framework for conducting research and operational distributed hydrologic simulations. EF5 consists of multiple components including water balance, river routing and inundation models that can be implemented jointly to simulate flood processes.

Three models of EF5 were used in this study: the Coupled Routing and Excess Storage (CREST; Wang et al. 2011) as a water balance model, the kinematic wave routing (Lighthill and Whitham 1955) as a routing model, and the simple mass-conserving inundation as an inundation model. The mass-conserving inundation model is a simple model that computes inundation based on stream flows and cross-sectional area and has been used widely in many studies (Bates and De Roo 2000; Horritt and Bates 2002; Bates et al. 2003; Chen et al. 2009). Computing cross-sectional area in mass-conserving inundation model is defined as follows:

$$
A=\left(\frac{Q}{\alpha}\right)^{\frac{1}{\beta}}
$$

where $A$ is the cross-sectional area $\left(\mathrm{m}^{2}\right), Q$ is the discharge $\left(\mathrm{m}^{3} \mathrm{~s}^{-1}\right)$, and $\alpha$ and $\beta$ are parameters governing routing and overland flow. These two parameters were calibrated using the resulting cloud-free flood maps; additional parameters of the model along with $\alpha$ and $\beta$ are described in Table 1.

\section{2) CALibration SCHEME}

Surface runoff and routing parameters were calibrated first to ensure the accuracy of the flood inundation model. The year 2012 was selected as the calibration period with calibration cascading from upstream to downstream 
TABLE 1. Hydrologic model parameters.

\begin{tabular}{|c|c|c|c|}
\hline Model & Parameter & Unit & Description \\
\hline \multirow[t]{6}{*}{ CREST } & WM & $\mathrm{mm}$ & Maximum soil water capacity \\
\hline & $B$ & - & Exponent of the variable infiltration curve \\
\hline & IM & - & Impervious area ratio \\
\hline & $\mathrm{KE}$ & - & $\begin{array}{l}\text { Multiplier to convert between input potential evapotranspiration and local actual } \\
\text { evapotranspiration }\end{array}$ \\
\hline & FC & $\mathrm{mm} \mathrm{h}^{-1}$ & Soil saturated hydraulic conductivity \\
\hline & IWU & $\%$ & Initial value of soil water \\
\hline \multirow[t]{7}{*}{ Kinematic } & $\mathrm{TH}$ & - & $\begin{array}{l}\text { Threshold for how many cells must drain into a cell for it to become part of a river in } \\
\text { the model }\end{array}$ \\
\hline & UNDER & - & Interflow flow speed multiplier \\
\hline & LEAKI & $\%$ & Amount of water leaking out of the interflow reservoir at each time step \\
\hline & ISU & $\mathrm{mm}$ & Initial value of the interflow reservoir \\
\hline & ALPHA & - & Multiplier in the equation $Q=\alpha A^{\beta}$ governs routing \\
\hline & BETA & - & Exponent in the equation $\widetilde{Q}=\alpha A^{\beta}$ governs routing \\
\hline & ALPHA0 & - & Multiplier in the equation $Q=\alpha A^{0.6}$ governs overland flow \\
\hline \multirow[t]{2}{*}{ Mass conservation } & ALPHA & - & Multiplier in the equation $\widetilde{A}=(Q / \alpha)^{1 / \beta}$ used for computing cross-sectional area \\
\hline & BETA & - & Exponent in the equation $A=(Q / \alpha)^{1 / \beta}$ used for computing cross-sectional area \\
\hline
\end{tabular}

stations. We chose the year 2012 to match with the calibration period for inundation parameters. The discharge dataset used for calibration was obtained from USGS streamflow observations; calibration was performed using the Shuffled Complex Evolution (SCE-UA) algorithm (Duan et al. 1992) to optimize the objective function of Nash-Sutcliffe efficiency (NSE). The SCE-UA optimization algorithm was proven accurate and robust in calibrating hydrologic parameters (Ajami et al. 2004; Barati et al. 2014; Eckhardt and Arnold 2001; Duan et al. 1994; Lin et al. 2006; Liong and Atiquzzaman 2004; Madsen 2000; Naeini et al. 2018; Sorooshian et al. 1993; Toth et al. 2000; Yang et al. 2015; Yapo et al. 1996).

Next, we calibrated inundation parameters using the flood maps. In a 4-month period from June to September 2012, we calibrated inundation parameters using the flood maps as a benchmark. Inundation maps simulated by the model were classified into water-covered/no water-covered maps and then compared with the flood maps (Fig. 4). The objective function used is false alarm ratio (FAR) in order to reduce pixels falsely simulated as inundated (i.e., overestimation).

We used two types of flood maps for inundation calibration: ones polluted by clouds and ones with cloud-free. Comparing a simulated inundation map to a cloud-free flood map was straightforward since they both did not have missing data (i.e., clouds). On the contrary, we had to mask out clouds in contaminated MODIS flood maps prior comparing the model outputs to them.

With regard to calibration of inundation models, since we used EF5 in this research as a semidistributed model, parameters of each station's governing hydrologic characteristics for a specified region based on topography. Hence, spatial distribution of stations also played an important role to make the simulated flood extents match with the observed ones. In our experiment, we took into account parameters of basin stations in the optimization scheme so that the "observed" cloud-free flood maps can help to reduce simulated overflows. It should be highlighted that this process required a lot of computational power. Here we used actual numbers of one calibration run to illustrate this. We calibrated using 11 stations and each station had two parameters, hence there were 22 parameters to be tuned. According to the SCE-UA, the number of points in each simplex is as follows:

$$
N_{\text {point }}^{(1)}=2 N_{\text {params }}+1,
$$

where $N_{\text {point }}^{(1)}$ is a number of points in the first simplex, $N_{\text {params }}$ is the number of parameters that need to be optimized given $N_{\text {params }}=22, N_{\text {point }}^{(1)}=2 \times 22+1=45$ points. Furthermore, if we used a typical number of five simplexes, the total number of points would be 225 points. For each iteration of the algorithm, if we ran the model to simulate inundation maps for four summer months in 2012, the computation time could take up to $3 \mathrm{~h}$. The calibration process running sequentially with 100 iterations could take 2 weeks to finish. Therefore, we parallelized the SCE-UA to be able to work with a larger number of iterations in order to find the global optimum. All simulations were run in our university's High-Performance Computing Cluster (HPC; https://hpc.oit.uci.edu/).

\section{Results}

\section{a. Validation of cloud-free flood maps}

The validation period of 2013 and 2014 was selected to investigate summer floods in the region. Specifically, 


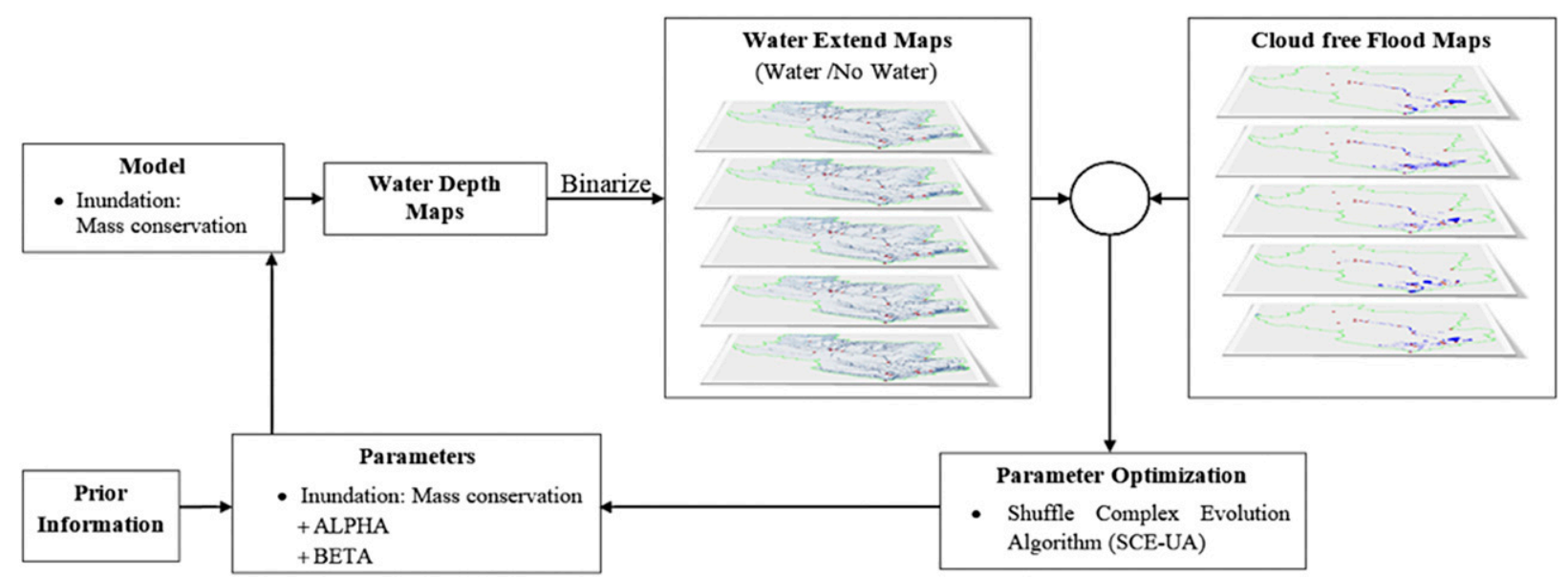

FIG. 4. Inundation parameters calibration scheme.

there was a record rainfall in Minnesota, Iowa, Wisconsin, and Illinois in the summer of 2014 (Breslin 2014). Also, in 2013, Landsat-8 started capturing high-quality, highresolution images of the surface, which was a valuable tool to benchmark the outputs from MODIS and model simulations.

The derived flood maps from Landsat- 8 were used to validate the cloud-free flood maps. To map floods from Landsat images, we used the NDWI. The index was based on Landsat- 8 green and near-infrared bands (band 3 and band 5, respectively):

$$
\text { NDWI }=\frac{\text { band } 3-\text { band } 5}{\text { band } 3+\text { band } 5} \text {. }
$$

When the NDWI was greater than or equal to 0 , the pixel was classified as water-covered (McFeeters 1996; Huang et al. 2018). The Landsat flood product was then resampled using the nearest neighbor method into $250-\mathrm{m}$ spatial resolution and reprojected into the same geographic coordinate system with the other two MODIS products. On average, around 600000 pixels were taken into account for categorical validation.

For validation, we compared the MWP product with the cloud-free flood maps (Cloud-free) using three categorical validation indices: probability of detection (POD), FAR, and Hanssen-Kuipers (HK) skill score (Hanssen and Kuipers 1965). There were four combinations of flood maps (flooded or not flooded) and ground truth: 1) hit: the MODIS pixel showed as flood, and so did the Landsat one; 2) miss: the MODIS pixel did not show as flood, but the Landsat one did; 3) false: the MODIS pixel showed as flood, but the Landsat one did not; 4) correct negative: neither the MODIS nor Landsat pixel showed as flood.

$$
\begin{aligned}
\text { POD } & =\frac{\text { hit }}{\text { hit }+ \text { miss }}, \\
\text { FAR } & =\frac{\text { false }}{\text { hit }+ \text { false }}, \text { and } \\
\text { HK } & =\frac{\text { hit } \times \text { correct negative }- \text { false } \times \text { miss }}{(\text { hit }+ \text { miss }) \times(\text { correct negative }+ \text { false })} .
\end{aligned}
$$

From Table 2, the cloud-free flood extents derived in this study had a higher POD and HK than the MWP. While the VI algorithm helped to increase the POD, it also falsely classified some cloud pixels as watercovered, which resulted in higher FAR of cloud-free flood maps than MWP in more than half of the test cases. The main reasons for this overestimation compared to MWP and explained by higher FAR values were the following. First, it is important to realize that this overestimation was relative to MWP. Second, clouds tended to cover most of the flooded area during a storm, especially true in flat-floored valleys as in some parts of the UMRB, which led to an alignment between cloud pattern and inundation (Smith 2002; Pierdicca et al. 2008; Jung et al. 2014). Thus, in MWP, when all clouds were masked from the flood inundation map, the probability that the remaining pixels be classified mistakenly as water-covered was relatively low. On the contrary, in our product, there was a higher probability of mistakenly identified water-covered pixels. By careful examination of the cloud percentage masked in MWP, one would find that our product relatively overestimated flooded area to MWP in days where cloud percentage in MWP was very high.

In general, over the period the cloud-free flood maps had an average POD, FAR, and HK of 0.49, 0.21, and 0.48 , respectively, whereas the corresponding numbers for MWP were $0.29,0.17$, and 0.29 , respectively. 
TABLE 2. Categorical validation of MWP and the cloud-free flood map. Bold values represent better metric performance.

\begin{tabular}{|c|c|c|c|c|c|c|c|}
\hline \multirow[b]{2}{*}{ Date } & \multicolumn{2}{|c|}{ POD } & \multicolumn{2}{|c|}{ FAR } & \multicolumn{2}{|c|}{ HK } & \multirow[b]{2}{*}{ Cloud percentage } \\
\hline & MWP & Cloud-free & MWP & Cloud-free & MWP & Cloud-free & \\
\hline 7 Jun 2013 & 0.49 & 0.57 & 0.35 & 0.49 & 0.48 & 0.51 & 70.42 \\
\hline 25 Jul 2013 & 0.26 & $\mathbf{0 . 5 2}$ & 0.07 & 0.06 & 0.26 & 0.52 & 79.15 \\
\hline 1 Aug 2013 & 0.24 & 0.33 & 0.26 & 0.07 & 0.23 & 0.33 & 31.37 \\
\hline 10 Aug 2013 & 0.27 & 0.54 & 0.30 & 0.16 & 0.27 & $\mathbf{0 . 5 3}$ & 60.61 \\
\hline 26 Aug 2013 & 0.38 & 0.43 & 0.13 & 0.27 & 0.38 & 0.43 & 36.07 \\
\hline 28 Jul 2014 & 0.18 & 0.68 & 0.09 & 0.18 & 0.18 & 0.60 & 80.15 \\
\hline 13 Aug 2014 & 0.36 & 0.50 & 0.06 & 0.21 & 0.36 & 0.50 & 17.22 \\
\hline 29 Aug 2014 & 0.17 & 0.38 & 0.08 & 0.27 & 0.17 & 0.38 & 73.78 \\
\hline Average & 0.29 & 0.49 & 0.17 & 0.21 & 0.29 & 0.48 & 56.10 \\
\hline
\end{tabular}

Figure 5 visualizes the flood maps before and after removing clouds on 28 July 2014. When dense clouds blocked satellites from capturing images in MWP, VI recovered most of the upper Mississippi River hindered by clouds.

\section{b. Validation of simulated streamflow}

After calibration of runoff and routing parameters, the EF5 was run for the period 2013 and 2014. Simulated discharges from nine stations were validated with observed values (Fig. 6).

For six stations along the upper Mississippi River (Brainerd, St. Paul, Hasting, Winona, Clinton, and Keokuk) from upstream to downstream, the correlation coefficient and NSE increased as the discharge increased (six graphs on the left of Fig. 6). For the other three stations in tributary rivers, the average of correlation coefficient and NSE were 0.80 and 0.54 , respectively (three graphs on the right of Fig. 6).

\section{c. Validation of simulated inundation maps}

Simulated inundation maps from two calibration schemes were validated with derived flood maps from Landsat. As mentioned in section $2 \mathrm{~b}$, only Landsat- 8 images with less than $15 \%$ area covered by clouds were selected. All the images were captured along a part of the Mississippi River between Winona and Clinton stations. Specifically, images on 14 June, 30 June, 16 July, and 1 August 2013 covered Winona, McGregor, and Muscoda stations, the rest of the images covered McGregor, Clinton, Conesville, and Joslin stations. On average, flow condition in the above referenced dates in the nearby streamflow gauges was $137 \%$ higher than normal conditions. Especially on 26 June 2014 , flow in all stations was $360 \%$ higher than in normal conditions.

In all validation scenes, the model calibrated using cloud-free flood maps produced lower FAR inundation maps (i.e., less overestimation) than the one calibrated using contaminated MODIS flood maps. On average,
FAR were 0.49 and 0.61 for two calibration scenarios, respectively. From Table 3, the inundation maps from the cloud-free calibrated model have higher average POD and HK than the inundation maps from model in other case: 0.87 and 0.84 for POD and HK, respectively, for the former case, compared to 0.70 and 0.67 for POD and $\mathrm{HK}$, respectively, for the latter case.

\section{Discussions and conclusions}

Through this study, we have addressed and resolved two main issues related to clouds of the MWP product. First, by determining cloud shadow positions based on the Luo et al. (2008) method, we were able to reduce false cloud shadow pixels classified as water covered. Second, by applying the VI algorithm, we can completely and accurately remove clouds from MODIS flood maps. Based on polluted images captured during flood events, the VI algorithm could provide clearly dynamic changes in flooded areas. In Fig. 5, flooded areas detected in the Landsat images were captured by the resulting cloud-free MODIS flood maps.

Through comparison against Landsat- 8 observations, we found that the VI algorithm can effectively remove clouds from MODIS flood maps. After comparing with MWP, which also uses the same watercovered detection algorithm, VI removed most of the cloud-hindered parts of the Upper Mississippi River, thus providing information about the dynamics of flood events. In the validation period, the recovered MODIS flood maps had on average higher scores of POD and HK, 0.49 and 0.48 , respectively, in comparison with ones from MWP of 0.29 and 0.29, respectively. In Fig. 5, when validating the flood maps before and after removing clouds on 28 July 2014, most of the cloud-free pixels of MWP were missed in cloud-free flood map. This issue had already been mentioned in the product evaluation (Nigro et al. 2014). Nigro et al. (2014) found that scan angles and small water-covered body size could reduce the amount of permanent water-covered detected. 

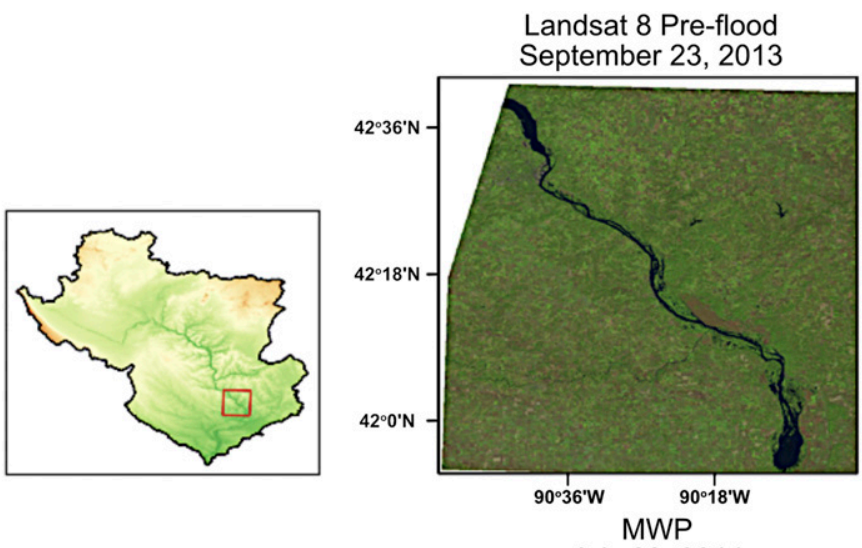

July 28, 2014

\begin{tabular}{ccc}
\hline & MWP & $\begin{array}{c}\text { Cloud-free } \\
\text { flood map }\end{array}$ \\
\hline POD & 0.18 & $\underline{\mathbf{0 . 6 8}}$ \\
FAR & $\underline{\mathbf{0 . 0 9}}$ & 0.18 \\
HK & 0.18 & $\underline{\mathbf{0 . 6 0}}$ \\
\hline
\end{tabular}

July 28,2014

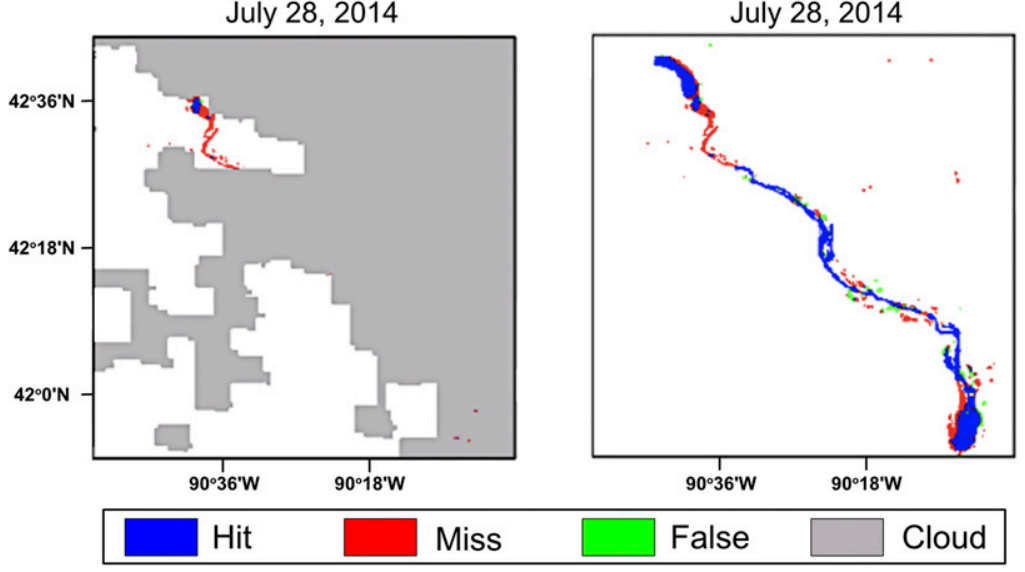

FIG. 5. Cloud-free MODIS flood map detection in the UMRB on 28 July 2014.

Moreover, when compared to the static water-covered layer [MOD44W; i.e., section 3a(5)], 95\% of hit pixels of the cloud-free flood map overlapped with the permanent water-covered.

Inundated pixels (water-covered pixels that fell outside the static water-covered bodies) contributed to $5 \%$ of hit pixels and were located at the middle of the river reach. Miss pixels at the edges also belonged to the permanent water-covered bodies. This "shrink" effect was caused by a prolonged cloudy period.

While determining static waterbody is quite straight forward, detecting flooded areas that are cloud polluted is much more complicated and might require merging data from many sources (e.g., gauges, drones or modeling). Our approach is robust which only needs waterbody information of images before or after the day, and thus can be applied in other areas where only satellite images are available. The VI is based on the gradient change of waterbodies to estimate missing data. In flat terrains, water generally moves slower than in steep areas so unless clouds persist for an extraordinary time (greater than 5 days), the VI could accurately reconstruct the whole waterbody in the floodplains.
With regard to calibrating hydrologic parameters, the overall results for the validation periods were satisfactory. Integrating cloud-free flood observations improved flood inundation modeling. When validated with Landsat-8's flood extents, the average POD and FAR of inundation maps were 0.87 and 0.49 , respectively. On the contrary, performance of the flood inundation model calibrated with cloud-contaminated MODIS flood maps was less accurate compared to the use of cloud-free flood maps as evident by the increase in average HK from 0.67 to 0.84 , respectively. During cloudy days, only a small part of the water-covered extent was captured in the MODIS images. This reemphasized the importance of considering cloud-free water-covered extent of the whole basin when calibrating model's inundation parameters.

The calibration process was constrained by computational resources and data availability. We selected the closest year to the validation period, which had streamflow data of all 11 USGS stations with the expectation of reflecting the hydrometeorology trend.

It is worth noting that, in some cases, flood extents produced by VI were overestimated, since we used the 

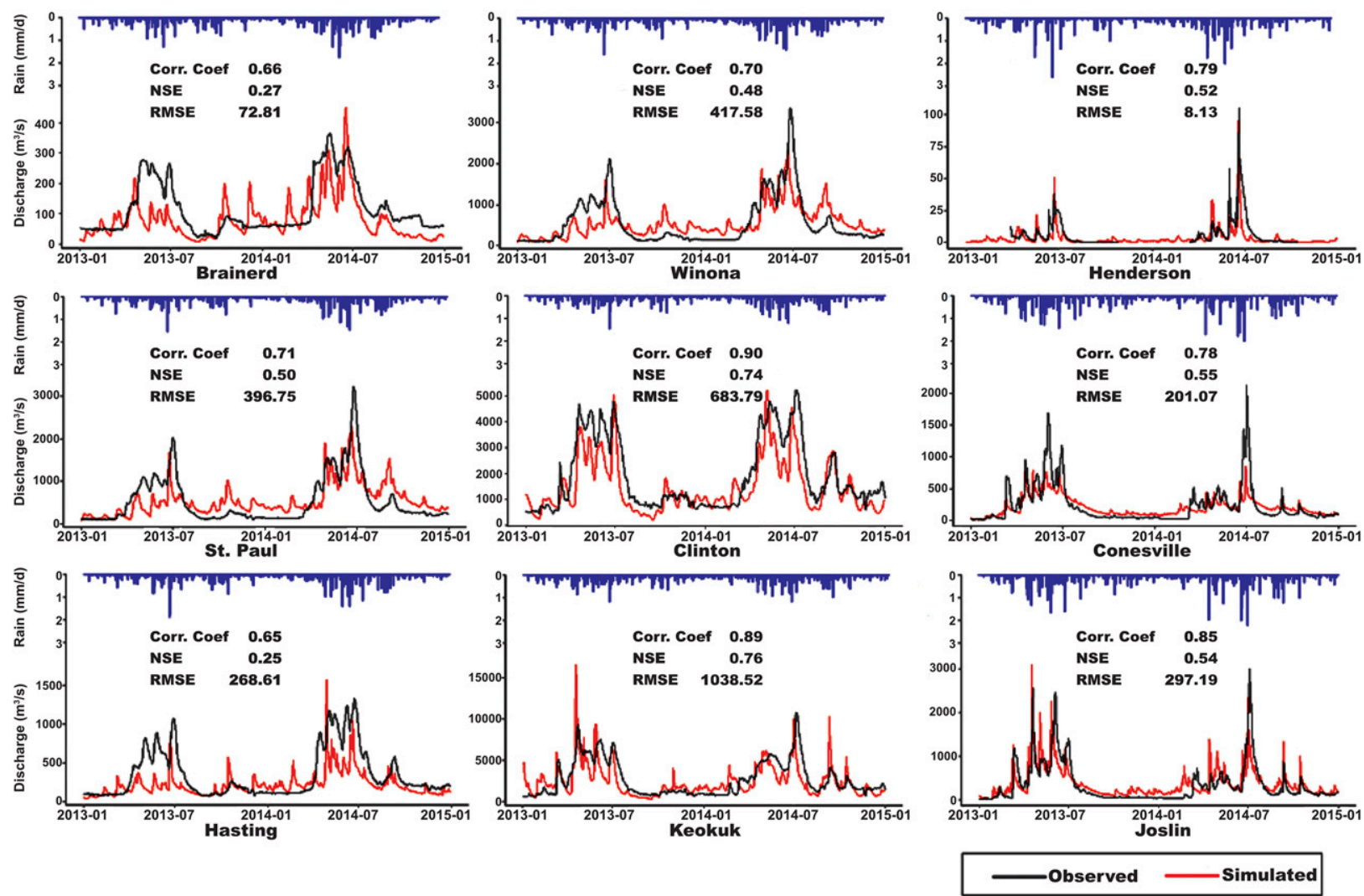

FIG. 6. Discharge validation for stations in the UMRB in 2013 and 2014.

interpolation period of 15 days to fully take into account dynamic changes of the water-covered bodies. This led to days when floods were retreating; VI estimated water-covered in these days by taking watercovered body boundaries information from both their ascending and preceding days. While the preceding days had more inundated area, the construct 3D watercovered body surface could change the speed of flood retreating (making it faster or slower). The latter would lead to overestimate the inundation areas.

There are a few areas for future investigation. First is adapting the current water-covered detection algorithm of Brakenridge to different land cover types. This arose since Nigro et al. (2014) reported that while the algorithm performed well in cropland areas, it underdetected floods that occurred in barren and sparsely

TABLE 3. Categorical validation of inundation maps from EF5 models calibrated with cloud-contaminated and cloud-free flood maps. Bold values represent better metric performance.

\begin{tabular}{|c|c|c|c|c|c|c|}
\hline \multirow[b]{2}{*}{ Date } & \multicolumn{2}{|l|}{ POD } & \multicolumn{2}{|l|}{ FAR } & \multicolumn{2}{|l|}{ HK } \\
\hline & Cloud-contaminated & Cloud-free & Cloud-contaminated & Cloud-free & Cloud-contaminated & Cloud-free \\
\hline 14 Jun 2013 & 0.75 & 0.89 & 0.81 & 0.46 & 0.69 & 0.87 \\
\hline 30 Jun 2013 & 0.69 & 0.92 & 0.72 & 0.63 & 0.67 & 0.90 \\
\hline 16 Jul 2013 & 0.63 & 0.83 & 0.40 & 0.32 & 0.62 & 0.81 \\
\hline 1 Aug 2013 & 0.78 & 0.77 & 0.41 & 0.38 & 0.77 & 0.75 \\
\hline 10 Aug 2013 & 0.73 & 0.91 & 0.59 & 0.57 & 0.71 & 0.89 \\
\hline 26 Aug 2013 & 0.57 & 0.84 & 0.71 & 0.55 & 0.55 & 0.81 \\
\hline 26 Jun 2014 & 0.63 & 0.82 & 0.52 & 0.31 & 0.62 & 0.78 \\
\hline 28 Jul 2014 & 0.71 & 0.87 & 0.63 & 0.52 & 0.69 & 0.85 \\
\hline 13 Aug 2014 & 0.72 & 0.89 & 0.58 & 0.56 & 0.70 & 0.86 \\
\hline 29 Aug 2014 & 0.75 & 0.93 & 0.73 & 0.61 & 0.72 & 0.89 \\
\hline Average & 0.70 & 0.87 & 0.61 & 0.49 & 0.67 & 0.84 \\
\hline
\end{tabular}


vegetated areas. Second is filtering out parts of rivers or streams where clouds persist over time (e.g., more than 5 days). Prolonged cloud cover limits the VI to gather enough information for accurate detection of water-covered bodies.

Acknowledgments. This research was partially supported by the ICIWaRM of the U.S. Army Corps of Engineers, UNESCO's G-WADI program, Cooperative Institute for Climate and Satellites (CICS) program (NOAA Prime Award NA14NES4320003, Sub-Award 2014-2913-03) for OHD-NWS student fellowship, Army Research Office (Award W911NF-11-1-0422), National Science Foundation (NSF Award 1331915), Department of Energy (DoE Prime Award DE-IA0000018), and California Energy Commission (CEC Award 300-15-005).

\section{REFERENCES}

Ajami, N. K., H. Gupta, T. Wagener, and S. Sorooshian, 2004: Calibration of a semi-distributed hydrologic model for streamflow estimation along a river system. J. Hydrol., 298 , 112-135, https://doi.org/10.1016/j.jhydrol.2004.03.033.

Alsdorf, D., E. Rodriguez, and D. Lettenmaier, 2007: Measuring surface water from space. Rev. Geophys., 45, RG2002, https:// doi.org/10.1029/2006RG000197.

Andreadis, K. M., G. J.-P. Schumann, and T. Pavelsky, 2013: A simple global river bankfull width and depth database. Water Resour. Res., 49, 7164-7168, https://doi.org/10.1002/wrcr.20440.

Barati, R., S. S. Neyshabouri, and G. Ahmadi, 2014: Sphere drag revisited using shuffled complex evolution algorithm. River Flow 2014, A. J. Schleiss et al., Eds, Taylor \& Francis Group, 345-353.

Bates, P. D., and A. J. De Roo, 2000: A simple raster-based model for flood inundation simulation. J. Hydrol., 236, 54-77, https:// doi.org/10.1016/S0022-1694(00)00278-X.

_, J. Marks, and M. S. Horritt, 2003: Optimal use of highresolution topographic data in flood inundation models. $H y$ drol. Processes, 17, 537-557, https://doi.org/10.1002/hyp.1113.

Begnudelli, L., B. F. Sanders, and S. F. Bradford, 2008: Adaptive Godunov-based model for flood simulation. J. Hydraul. Eng., 134, https://doi.org/10.1061/(ASCE)0733-9429(2008) 134:6(714).

Brakenridge, R., and E. Anderson, 2006: MODIS-based flood detection, mapping and measurement: The potential for operational hydrological applications. Transboundary Floods: Reducing Risks through Flood Management, J. Marsalek, G. Stancalie, and G. Balint, Eds., Nato Science Series: IV: Earth and Environmental Sciences, Vol. 72, Springer, 1-12.

Breslin, S., 2014: Midwest flooding crisis: More rainfall means more flooding for Iowa, Minnesota. Weather.com, accessed 5 July 2014 , https://weather.com/safety/floods/news/persistent-midwestflooding-20140625.

Carroll, M. L., C. M. DiMiceli, J. R. G. Townshend, R. A. Sohlberg, A. B. Hubbard, and M. R. Wooten, 2017: MOD44W: Global MODIS water maps user guide. 17 pp., https://lpdaac.usgs.gov/ documents/109/MOD44W_User_Guide_ATBD_V6.pdf.

Chen, J., A. A. Hill, and L. D. Urbano, 2009: A GIS-based model for urban flood inundation. J. Hydrol., 373, 184-192, https:// doi.org/10.1016/j.jhydrol.2009.04.021.
Condon, L. E., and R. M. Maxwell, 2019: Modified priority flood and global slope enforcement algorithm for topographic processing in physically based hydrologic modeling applications. Comput. Geosci., 126, 73-83, https://doi.org/10.1016/ j.cageo.2019.01.020.

Di Baldassarre, G., G. Schumann, and P. D. Bates, 2009: A technique for the calibration of hydraulic models using uncertain satellite observations of flood extent. J. Hydrol., 367, 276-282, https://doi.org/10.1016/j.jhydrol.2009.01.020.

Douglas, D. H., and T. K. Peucker, 1973: Algorithms for the reduction of the number of points required to represent a digitized line or its caricature. Cartographica, 10, 112-122, https:// doi.org/10.3138/FM57-6770-U75U-7727.

Duan, Q., S. Sorooshian, and V. Gupta, 1992: Effective and efficient global optimization for conceptual rainfall-runoff models. Water Resour. Res., 28, 1015-1031, https://doi.org/ 10.1029/91WR02985.

- —_, and ——, 1994: Optimal use of the SCE-UA global optimization method for calibrating watershed models. J. Hydrol., 158, 265-284, https://doi.org/10.1016/0022-1694(94) 90057-4.

Duchon, J., 1977: Splines minimizing rotation-invariant seminorms in Sobolev spaces. Constructive Theory of Functions of Several Variables, W. Schempp and K. Zeller, Eds., Lecture Notes in Mathematics, Vol. 571, Springer, 85-100.

Eckhardt, K., and J. G. Arnold, 2001: Automatic calibration of a distributed catchment model. J. Hydrol., 251, 103-109, https:// doi.org/10.1016/S0022-1694(01)00429-2.

FEWSNET, 2019: FEWS data downloads. Accessed 29 March 2019, https://earlywarning.usgs.gov/fews/datadownloads.

Flamig, Z., H. Vergara, R. Clark, J. J. Gourley, and Y. Hong, 2015: EF5: Ensemble framework for flash flood forecasting. Accessed April 13, 2018, http://ef5.ou.edu/.

Gobeyn, S., and Coauthors, 2017: Impact of the timing of a SAR image acquisition on the calibration of a flood inundation model. Adv. Water Resour., 100, 126-138, https://doi.org/10.1016/ j.advwatres.2016.12.005.

Hanssen, A. W., and W. J. A. Kuipers, 1965: On the relationship between the frequency of rain and various meteorological parameters. Mededelingen en verhandelingen 81, Koninklijk Nederlands Meteorologisch Institut, 2-15.

Horritt, M. S., and P. D. Bates, 2002: Evaluation of 1D and 2D numerical models for predicting river flood inundation. J. Hydrol., 268, 87-99, https://doi.org/10.1016/S0022-1694(02) 00121-X.

Hostache, R., P. Matgen, G. Schumann, C. Puech, L. Hoffmann, and L. Pfister, 2009: Water level estimation and reduction of hydraulic model calibration uncertainties using satellite SAR images of floods. IEEE Trans. Geosci. Remote Sens., 47, 431441, https://doi.org/10.1109/TGRS.2008.2008718.

Huang, C., Y. Chen, S. Zhang, and J. Wu, 2018: Detecting, extracting, and monitoring surface water from space using optical sensors: A review. Rev. Geophys., 56, 333-360, https:// doi.org/10.1029/2018RG000598.

Jung, Y., D. Kim, D. Kim, M. Kim, and S. O. Lee, 2014: Simplified flood inundation mapping based on flood elevationdischarge rating curves using satellite images in gauged watersheds. Water, 6, 1280-1299, https://doi.org/10.3390/ w6051280.

Krajewski, W., and Coauthors, 2017: Real-time flood forecasting and information system for the state of Iowa. Bull. Amer. Meteor. Soc., 98, 539-554, https://doi.org/10.1175/ BAMS-D-15-00243.1. 
Lighthill, M. J., and G. B. Whitham, 1955: On kinematic waves II. A theory of traffic flow on long crowded roads. Proc. Roy. Soc. London, 229A, 317-345, https://doi.org/10.1098/rspa.1955.0089.

Lin, J.-Y., C.-T. Cheng, and K.-W. Chau, 2006: Using support vector machines for long-term discharge prediction. Hydrol. Sci. J., 51, 599-612, https://doi.org/10.1623/hysj.51.4.599.

Lin, Y., 2011: GCIP/EOP Surface: Precipitation NCEP/EMC 4KM Gridded Data (GRIB) Stage IV Data. Version 1.0, NCAR, accessed 29 March 2019, https://doi.org/10.5065/D6PG1QDD.

Liong, S.-Y., and M. Atiquzzaman, 2004: Optimal design of water distribution network using shuffled complex evolution. J. Inst. Eng. Singapore, 44, 93-107.

Luo, Y., A. P. Trishchenko, and K. V. Khlopenkov, 2008: Developing clear-sky, cloud and cloud shadow mask for producing clear-sky composites at 250-meter spatial resolution for the seven MODIS land bands over Canada and North America. Remote Sens. Environ., 112, 4167-4185, https://doi.org/10.1016/j.rse.2008.06.010.

Madsen, H., 2000: Automatic calibration of a conceptual rainfallrunoff model using multiple objectives. J. Hydrol., 235, 276288, https://doi.org/10.1016/S0022-1694(00)00279-1.

McFeeters, S. K., 1996: The use of the normalized difference water index (NDWI) in the delineation of open water features. Int. J. Remote Sens., 17, 1425-1432, https://doi.org/10.1080/ 01431169608948714.

Moll, J. R., and J. F. M. Overmars, 1990: River hydrometry by pattern recognition in remote sensing images. Int. Symp. on Remote Sensing and Water Resources, Enschede, The Netherlands, Delft Hydraulics Laboratory, $10 \mathrm{pp}$.

Monteith, J. L., 1965: Evaporation and environment. Symp. Soc. Exp. Biol., 19, 205-234.

- 1973: Principles of Environmental Physics. Arnold, 440 pp.

Naeini, M. R., T. Yang, M. Sadegh, A. AghaKouchak, K. Hsu, S. Sorooshian, Q. Duan, and X. Lei, 2018: Shuffled ComplexSelf Adaptive Hybrid EvoLution (SC-SAHEL) optimization framework. Environ. Modell. Software, 104, 215-235, https:// doi.org/10.1016/j.envsoft.2018.03.019.

NASA, 2019: NASA Shuttle Radar Topography Mission Water Body Data Shapefiles \& Raster Files V003. https://catalog.data.gov/ dataset/nasa-shuttle-radar-topography-mission-water-bodydata-shapefiles-raster-files-v003.

Nguyen, P., A. Thorstensen, S. Sorooshian, K. Hsu, and A. AghaKouchak, 2015: Flood forecasting and inundation mapping using HiResFlood-UCI and near-real-time satellite precipitation data: The 2008 Iowa flood. J. Hydrometeor., 16, 1171-1183, https://doi.org/10.1175/JHM-D-14-0212.1.

, and Coauthors, 2016: A high resolution coupled hydrologic-hydraulic model (HiResFlood-UCI) for flash flood modeling. J. Hydrol., 541, 401-420, https://doi.org/ 10.1016/j.jhydrol.2015.10.047.

Nigro, J., D. Slayback, F. Policelli, and R. Brakenridge, 2014: NASA/DFO MODIS Near Real-Time (NRT) Global Flood Mapping Product Evaluation of Flood and Permanent Water Detection. NASA Goddard Space Flight Center, 27 pp., https://floodmap.modaps.eosdis.nasa.gov/documents/ NASAGlobalNRTEvaluationSummary_v4.pdf.

Pierdicca, N., M. Chini, L. Pulvirenti, and F. Macina, 2008: Integrating physical and topographic information into a fuzzy scheme to map flooded area by SAR. Sensors, 8, 4151-4164, https://doi.org/10.3390/s8074151.

Policelli, F., and D. Slayback, 2017: NRT Global Flood Mapping. NASA, accessed 26 March 2019, https://floodmap.modaps.eosdis.nasa.gov.

Smith, L. C., 2002: Emerging applications of interferometric synthetic aperture radar (InSAR) in geomorphology and hydrology. Ann. Assoc. Amer. Geogr., 92, 385-398, https://doi.org/ 10.1111/1467-8306.00295.

Sorooshian, S., Q. Duan, and V. K. Gupta, 1993: Calibration of rainfall-runoff models: Application of global optimization to the Sacramento Soil Moisture Accounting Model. Water Resour. Res., 29, 1185-1194, https://doi.org/10.1029/92WR02617.

Toth, E., A. Brath, and A. Montanari, 2000: Comparison of shortterm rainfall prediction models for real-time flood forecasting. J. Hydrol., 239, 132-147, https://doi.org/10.1016/ S0022-1694(00)00344-9.

Tran, H., P. Nguyen, M. Ombadi, K. Hsu, S. Sorooshian, and Q. Xia, 2019: A cloud-free MODIS snow cover dataset for the contiguous United States from 2000 to 2017. Sci. Data, 6, 180300, https://doi.org/10.1038/sdata.2018.300.

Turk, G., and J. F. O'Brien, 1999: Shape transformation using variational implicit functions. SIGGRAPH '99: Proceedings of the 26th Annual Conference on Computer Graphics and Interactive Techniques, ACM Press/Addison-Wesley Publishing, 335-342, https://doi.org/10.1145/311535.311580.

UMBRA, 2003: River and basin facts. Upper Mississippi River Basin Association, accessed 13 April 2019, http://www.umrba.org/ facts.htm.

USGS, 2016: USGS Water Data for the Nation. Accessed 29 March 2019, https://doi.org/10.5066/F7P55KJN.

_ 2018: Landsat 8 (L8) Data Users Handbook Version 3. https:// www.usgs.gov/media/files/landsat-8-data-users-handbook.

_- 2019: EarthExplorer. Accessed 26 March 2019, https:// earthexplorer.usgs.gov.

Vermote, E., and R. Wolfe, 2015a: MOD09GA MODIS/Terra Surface Reflectance Daily L2G Global $1 \mathrm{~km}$ and $500 \mathrm{~m}$ SIN Grid V006. NASA EOSDIS LP DAAC, https://doi.org/10.5067/ MODIS/MOD09GA.006.

- and - 2015b: MOD09GQ MODIS/Terra Surface Reflectance Daily L2G Global 250m SIN Grid V006. NASA EOSDIS LP DAAC, https://doi.org/10.5067/MODIS/MOD09GQ.006.

Wang, J., and Coauthors, 2011: The coupled routing and excess storage (CREST) distributed hydrological model. Hydrol. Sci. J., 56, 84-98, https://doi.org/10.1080/02626667.2010.543087.

Xia, Q., X. Gao, W. Chu, and S. Sorooshian, 2012: Estimation of daily cloud-free, snow-covered areas from MODIS based on variational interpolation. Water Resour. Res., 48, W09523, https://doi.org/10.1029/2011WR011072.

Yang, T., X. Gao, S. L. Sellars, and S. Sorooshian, 2015: Improving the multi-objective evolutionary optimization algorithm for hydropower reservoir operations in the California OrovilleThermalito complex. Environ. Modell. Software, 69, 262-279, https://doi.org/10.1016/j.envsoft.2014.11.016.

Yapo, P. O., H. V. Gupta, and S. Sorooshian, 1996: Automatic calibration of conceptual rainfall-runoff models: Sensitivity to calibration data. J. Hydrol., 181, 23-48, https://doi.org/10.1016/ 0022-1694(95)02918-4. 